\title{
Method of Static Characteristics Calculation of Adjustable Two-Ring Type Full-Metal Vibroinsulators in a Non-Linear Approach
}

\author{
Vladimir S. Melentjev ${ }^{1} \&$ Alexander S. Gvozdev ${ }^{1}$ \\ ${ }^{1}$ Samara State Aerospace University (SSAU), Russia \\ Correspondence: Alexander S. Gvozdev, Samara State Aerospace University (SSAU), 443086, Samara, 34, \\ Moskovskoe shosse, Russia. E-mail: mtrushin@mail.ru
}

Received: June 27, 2014

Accepted: August 14, 2014

Online Published: January 28, 2015

doi:10.5539/mas.v9n2p320

URL: http://dx.doi.org/10.5539/mas.v9n2p320

\begin{abstract}
Full-metal vibroinsulators with circular elements are widely spread and effectively reduce a harmful impact of vibration in mechanical systems. However, in a contemporary literature an issue of a regulation of that kind of vibroinsulators and their study, considering non-linearity of the characteristics, is addressed insufficiently. In the presented study by a joint implementation of Mohr's method and finite element method the method of a calculation of loading characteristics of adjustable full-metal vibroinsulators with elastic elements in the form of an ellipse and a system of two ellipses was developed. Broad (in a few hundreds of times) capabilities to regulate their rigidity characteristics were demonstrated. The presence of zone of quasi-zero rigidity is detected. The method allows to accurately determine parameters of a vibroinsulator, which increases quality of final products.
\end{abstract}

Keywords: full-metal adjustable vibroinsulator, static characteristic, nonlinear elasticity theory, elastically damping element, elastic elliptical ring, adjustable rigidity, deformation of cable rings

\section{Introduction}

Modern full-metal vibroinsulators belong to devices that sustain significant strains during their operation, which are commensurable with a size of elastic elements (Nurkan, et al., 2006, Ao, et al., 2005, Ulanov, et al., 2009). In those circumstances there is a substantially non-linear dependence of large displacements from external forces, although a material of elastic elements of vibroinsulator behaves elastically because of small strains (Ulanov and Ponomarev, 2009, Popp, et al., 2003). Therefore, linear theory of elastic rods bending gives a great inaccuracy in a case of vibroinsulator's design.

A large number of vibroinsulator's structural arrangements made from MR (metal rubber) material, metal cables, packs of tapes with elastic elements contours in them in a form of arcs of circles (Ao, et al. 2006, Belousov, et al., 2009, Jiang, et al., 2008). Elastic elements in the specified vibroinsulators are flexible rings or parts of rings with friction distributed within their volume (Ponomarev, 2003). A complete theory for a calculation of flexible multi-layered elements doesn't exist until now. However, a calculation of characteristics of such elements, not considering distributed friction, were conducted by distinguished scientists of 19th and 20th centuries: J. Boussinesq, H. Lamb, A. Foppl, R. Mayer, S. Venant, S.P. Tymoshenko, E.P. Popov and others. (Ponomarev, 2003, Popov, 1986).

E.P. Popov established, that in a case of flexible ring's deformation by two forces, directed along the diameter toward each other, its characteristic is "soft"; in a case of a deformation by two diverging forces, it is "hard" (Popov, 1986).

Many structural designers of cable vibroinsulators made attempts to compensate a nonlinearity of loading characteristic of vibroinsulator with circular elements by entering additional joints and limiters (Mihir, 2011, Barry, et al., 2014, Ponomarev, 2003).

In the present study an attempt is made to develop a method for a design of vibroinsulators with circular elastic elements by entering additional elastic elements, which are working in opposite phase with other elements: when main circular elements are loaded by converging forces, additional elements are loaded by divergent loads and vice versa. Diagram of such structure is presented in Figure 1.

By correctly selecting a ratio of ring's rigidities, linearity of characteristics can be achieved in a working range. In addition, discussed vibroinsulator possesses a rich set of features that can be used to adjust and control loading 
characteristics of rings by altering length of a clamp, which are linking rings together (Yurddas, et al., 2012, Ulanov and Ponomarev, 2009). A change of clamps length an initial center line of ring, which is circle. The ring becomes ellipse, and a ratio of rigidities is changing.

For a calculation of two ellipse system, it is necessary to know loading characteristics of a single ellipse, which are substantially different from those of rings.

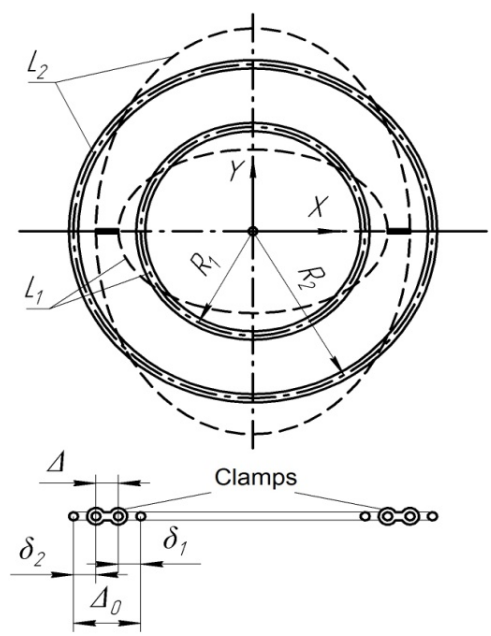

a)

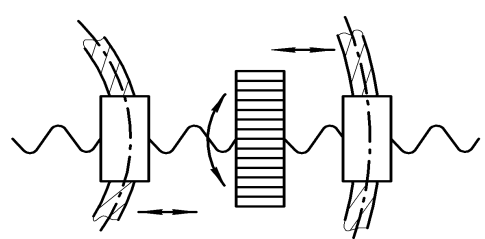

b)

Figure 1. Scheme of a vibroinsulator which consists of two rings

a) General scheme, where L1, L2 - length of elastic elements; R1, R2 - radius of elastic elements before bracing; $\delta 1, \delta 2$ [delta] - strain of elastic elements with bracing; $\Delta 0$ [delta] - distance between elastic elements before bracing; $\Delta$ [delta] - bracing length; b) Scheme of EDE (elastic damping element) shape's control, provided by changing length of a clamp

\section{Materials and Methods}

Vibroinsulator presented in Figure 2, operates as follows. Under a vibration load coming from a base or vibrating object, rings of EDE (elastic damping element) are becoming strained, compensating an action of applied loads and dissipating their energy. A regulation of EDE rigidity is carried out by a rotation a threaded rod leading to a change in a shape of internal and external EDE, due to a change of clamps length.

The presented vibroinsulator provides a desired uniformity of rigidity's values and resonance frequencies in a direction of main mutually orthogonal axes. Structural arrangement of EDE allows to adjust elastic characteristics of components in a wide range.

According to the studies, loading characteristics, if they are created in a linear approach, in a case of large strains, which is typical for elastic elements of vibroinsulator, give discrepancies with a magnitude of several times. Therefore, although a diagram of loading characteristics can be obtained in a linear form, rigidity must be searched for only with a consideration of non-linearity of strain, that is, depending on geometry of an ellipse.

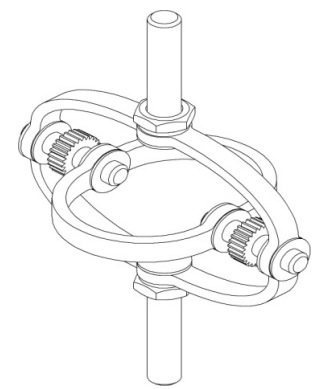

Figure 2. A version of vibroinsulator with EDE in a form of a set of rings

Introducing main designations: $\mathrm{P}$ - an external force, $[\mathrm{N}] ; \delta_{\mathrm{im}}[$ delta $]$ - strain of an ellipse, $[\mathrm{m}]$, where $\mathrm{i}-\mathrm{a}$ case of loading, $\mathrm{m}$ - a semiaxis of an ellipse; and - a big semiaxis of an ellipse, [m]; b - a small semiaxis of an ellipse, $[\mathrm{m}] ; \mathrm{k}_{\mathrm{m}}$ - coefficient of bending moment (appears in a case of a disclosure of static uncertainty), where $\mathrm{m}-\mathrm{a}$ 
semiaxis of an ellipse.

In contrast to a ring, in a case of an ellipse it is required to consider two specific cases of loading:

1. When force $P$ acts along a semiaxis;

2. When force $P$ acts along $b$ semiaxis.

At the same time, the condition of $a>b$ is always satisfied. For each case it is necessary to know strain in a direction of a force and strain in a perpendicular direction. Thus, for a solution of the problem it is enough to find four equations of loading characteristics of an ellipse for four combinations of forces directions and strains (in following, in order to save a space in the paper, introducing designations of $\mathrm{P} \| \mathrm{a}$ type, which means that an external force is collinear with a big semiaxis of an ellipse, $\mathrm{P} \| \mathrm{b}$ - an external force is a collinear with small semiaxis of an ellipse, $y \| a$ and $y \| b-$ the same for strain's directions).

Considering the case, when a force is applied and strain occurs along an ellipse's big semiaxis a (see Figure 3).

That system is statically indeterminable. Using already known method in order to disclose static indeterminateness.

A calculated, statically determinable system for that case is presented in figure 3. An equation of M moment, arising from disclosure of a static uncertainty, can be expressed in a following way:

$$
M=k_{a} P a, \quad \text { or } \quad M=k_{b} P b,
$$

depending on the direction of action of the force $\mathrm{P}$, where values of coefficient $\mathrm{k}_{\mathrm{a}}$ or $\mathrm{k}_{\mathrm{b}}$ for different ratios of semiaxes $\mathrm{a}$ and $\mathrm{b}$ for convenience are compiled in table 1.

Loading characteristics of the discussed system can be determined using Mohr's method.

$$
\delta=\frac{1}{E \cdot J} \cdot \int_{0}^{\frac{\pi}{2}} \bar{M}_{1} \cdot M_{P} \cdot d S .
$$

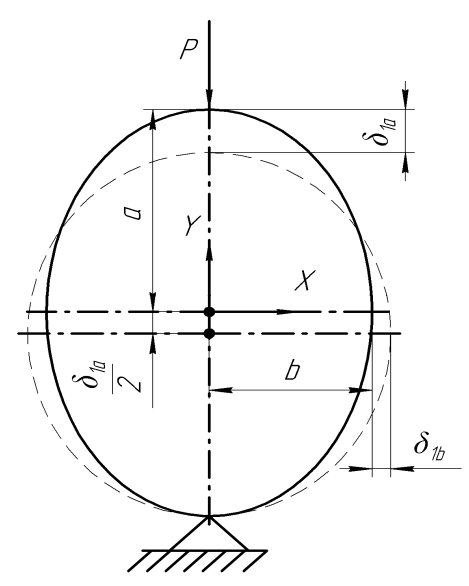

Figure 3. The first case of ellipse $\mathrm{P} \| \mathrm{a}$ strain

Table 1. Values of moment's coefficients for an ellipse

\begin{tabular}{rrrrrr}
\hline $\mathrm{a} / \mathrm{b}$ & 1.0 & 1.2 & 1.4 & 1.6 & 1.7 \\
\hline $\mathrm{k}_{\mathrm{a}}$ & 0.3183 & 0.2733 & 0.2400 & 0.2141 & 0.2032 \\
$\mathrm{k}_{\mathrm{b}}$ & 0.3183 & 0.3087 & 0.301 & 0.2946 & 0.2918 \\
$\mathrm{a} / \mathrm{b}$ & 1.8 & 2.0 & 2.2 & 2.4 & 2.5 \\
$\mathrm{k}_{\mathrm{a}}$ & 0.1934 & 0.1764 & 0.1622 & 0.1501 & 0.1447 \\
$\mathrm{k}_{\mathrm{b}}$ & 0.2893 & 0.2849 & 0.2812 & 0.2781 & 0.2767 \\
$\mathrm{a} / \mathrm{b}$ & 2.7 & 3.2 & 3.7 & 4.5 & 5.0 \\
$\mathrm{k}_{\mathrm{a}}$ & 0.1350 & 0.1155 & 0.1009 & 0.08391 & 0.07588 \\
$\mathrm{k}_{\mathrm{b}}$ & 0.2742 & 0.2693 & 0.2656 & 0.2616 & 0.2597 \\
$\mathrm{a} / \mathrm{b}$ & 5.5 & 6.5 & 7.5 & 9.0 & 10 \\
$\mathrm{k}_{\mathrm{a}}$ & 0.06923 & 0.05887 & 0.05119 & 0.04279 & 0.03857 \\
$\mathrm{k}_{\mathrm{b}}$ & 0.2582 & 0.2559 & 0.2542 & 0.2526 & 0.2517 \\
\hline
\end{tabular}


In order to solve that integral, it is necessary to know functions of bending moments along the length of a section. Expressing the equation for resulting bending moment MP from an external force $\mathrm{P}$ and the equation for a moment of a single force M1 in a direction of strain.

$$
\begin{aligned}
& M_{P}=k_{a} P a-\frac{P b}{2} \cdot \sin t, \\
& M_{1}=b \cdot \sin t .
\end{aligned}
$$

After integration and some mathematical operations, an expression for a determination of loading characteristics is obtained

$$
P=\frac{\delta_{1 a} E J}{a b K_{1}} .
$$

where $K_{1}-$ coefficient of form for the case 1 , when an axis of displacements is collinear with an external force $P$, which can be determine using the equation

$$
\begin{aligned}
& K_{1}=\frac{b}{3 e^{2}}\left(\left(1+e^{2}\right) \cdot E(e)-\left(1-e^{2}\right) \cdot F(e)\right)- \\
& -k_{a} a\left(\sqrt{1-e^{2}}+\frac{\arcsin (e)}{e}\right)
\end{aligned}
$$

It is established, that for all four cases of strain of an ellipse a single formula for a determination of load characteristics can be used

$$
P=\frac{\delta_{j} \cdot E J}{V_{j}},
$$

where $\mathrm{j}$ - cases of strain, discussed above; $\mathrm{V}_{\mathrm{j}}$ - coefficient, determined from (7).

$$
\begin{array}{cc}
I-\delta_{1 a} & V_{1 a}=a b K_{1} \\
I I-\delta_{1 b} & V_{1 b}=a^{2} K_{2} \\
I I I-\delta_{2 b} & V_{2 b}=a^{3} K_{3} \\
I V-\delta_{2 a} & V_{2 a}=a^{2} b K_{4}
\end{array}
$$

In this case $\delta_{1 a}$ [delta] the strain along the semiaxis a, $\delta_{1 b}$ [delta] the strain along the semiaxis b, when the force $\mathrm{P}$ acting along the semiaxis a. $\delta_{2 b}$ [delta] the strain along the semiaxis b, $\delta_{2 a}$ [delta] - the strain along the semiaxis $\mathrm{a}$, when the force $\mathrm{P}$ acting along the semiaxis $\mathrm{b}$.

$$
\begin{aligned}
& K_{2}=k_{a} a\left(1+\frac{1-e^{2}}{e} \ln \left(\frac{e+1}{\sqrt{1-e^{2}}}\right)\right)- \\
& -b \frac{1-\left(1-e^{2}\right)^{\frac{3}{2}}}{3 e^{2}} \\
& K_{3}=K_{3 \varsigma}=\frac{\left(1-e^{2}\right) \cdot F(e)+\left(2 e^{2}-1\right) \cdot E(e)}{3 e^{2}}- \\
& -2 k_{b}\left(\frac{1}{2}+\frac{1-e^{2}}{2 e} \ln \left(\frac{e+1}{\sqrt{1-e^{2}}}\right)\right) \\
& K_{4}=K_{4 \varsigma}=2 k_{b}\left(\frac{\sqrt{1-e^{2}}}{2}+\frac{\arcsin e}{2 e}\right)- \\
& -\frac{1-\left(1-e^{2}\right)^{\frac{3}{2}}}{3 e^{2}} .
\end{aligned}
$$

Conversing the discussed loading characteristic into dimensionless form. Analyzing relationship (4), using $\pi$-theorem (Hanche-Olsen, 2004). In the discussed expression $n=6$ of independent physical variables. $P, \delta$ [delta] $\mathrm{a}, \mathrm{b}, \mathrm{J}, \mathrm{E}$, and $\mathrm{k}=2$ of independent physical quantities: force $(\mathrm{N})$, length $(\mathrm{m})$. Then, according to $\pi$-theorem, a number of dimensionless criteria, which is sufficient for a purpose of a description of the system is $\mathrm{p}=\mathrm{n}-\mathrm{k}=4$. 
Dimensionless strain can be presented in a form of a ratio of strain of an ellipse to an initial radius of a curvature of a ring $\mathrm{R}_{0}$ :

$$
\varsigma_{1 a}=\frac{\delta_{1 a}}{R_{0}}=\frac{\pi \delta_{1 a}}{2 a E(e)} .
$$

Expressing the equation for a dimensionless force in a following form

$$
\beta=\frac{P R_{0}^{2}}{E J}=\frac{P \cdot\left(\frac{2 a E(e)}{\pi}\right)^{2}}{E J}=\frac{4 P a^{2} E^{2}(e)}{\pi^{2} E J} .
$$

The third dimensionless parameter - eccentricity of ellipse e - was introduced earlier. The indexes of dimensionless parameters correspond to the indexes dimensional parameters (7).

The criteria, which characterizes a size of a cable's cross section

$$
\chi=\frac{d}{R_{0}},
$$

where $\mathrm{d}$ - average diameter of a fine wire of an ellipse's cable.

Aside from aforementioned criteria of similarity, for that system parameter $\mathrm{n}$ can be considered, which determines a number of fine wires in an ellipse $\mathrm{n}_{\mathrm{w}}$. In that study $\mathrm{n}_{\mathrm{w}}=35$ (valid for the prevalent wire rope) is accepted as a permanent value.

In a dimensionless form, expressions for a determination of loading characteristics for each of cases will vary slightly, depending on along which semiaxis of ellipse strain is occurring.

For cases I and IV, when strain is determined along semiaxes a

$$
\beta=\frac{8 E^{3}(e) \cdot \varsigma_{i a}}{\sqrt{1-e^{2}} \cdot \pi^{3} \cdot K_{j \varsigma}},
$$

For cases II and III, when strain is determined along semiaxes b

$$
\beta=\frac{8 E^{3}(e) \cdot \varsigma_{i b}}{\pi^{3} K_{j \varsigma}},
$$

where $\mathrm{i}$ - a case of loading (force acts along big or small semiaxis of an ellipse); $\mathrm{j}$ - case of deformation. The values of shape coefficients $\mathrm{K}_{\mathrm{j}}$ and $\mathrm{K}_{\mathrm{j} \varsigma}$ also depend on number of cases of strain.

$$
\begin{aligned}
& K_{1 \varsigma}=\frac{\sqrt{1-e^{2}}}{3 e^{2}}\left(\left(1+e^{2}\right) \cdot E(e)-\left(1-e^{2}\right) \cdot F(e)\right)- \\
&-k_{a} \cdot\left(\sqrt{1-e^{2}}+\frac{\arcsin (e)}{e}\right) \\
& K_{2 \varsigma}=k_{a}\left(1+\frac{1-e^{2}}{e} \ln \left(\frac{e+1}{\sqrt{1-e^{2}}}\right)\right)- \\
&-\frac{\sqrt{1-e^{2}}}{3 e^{2}}\left(1-\left(1-e^{2}\right)^{\frac{3}{2}}\right)
\end{aligned}
$$

Knowing rigidity characteristics of one-ellipse system by two perpendicular axes, elastic-dampening properties of two-ellipse vibroinsulator can be calculated, which is presented below.

Discussing the case in which vibroinsulator, that consists of two rings (or ellipses) is braced by absolutely rigid clamps of $\Delta$ [delta] length. In that case, rings will deform and become ellipses, as shown in Figure 4, with a ratio of semiaxes of ellipses depends on a value of $\Delta$ [delta]. It is necessary to determine loading characteristics of that system in a linear apporach. Designated elastic element's parameters: 


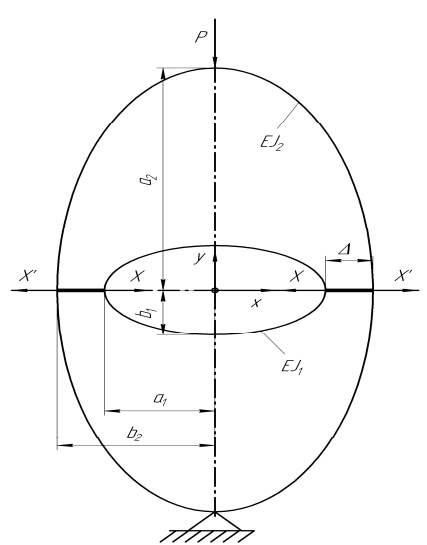

Figure 4. Scheme of two ellipse vibroinsulator

$\mathrm{R} 1$ - radius of the internal ring before bracing, [m]; R2 - radius of the external rings before bracing, [m]; a1 - a big semiaxis of an internal ellipse, [m]; b1 - a small semiaxis of an internal ellipse, [m]; a2 - a big semiaxis of an external ellipse, [m]; b2 - a small semiaxis of an external ellipse, [m]; J1 - moment of inertia of an internal ellipse's cross-section, [m4]; J2 - moment of inertia of an external ellipse cross section, [m4]; E - module of elasticity of a material, [Pa]

Solving the problem by following the algorithm:

1. Determining values of semiaxis of ellipses $\mathrm{a}_{1}, \mathrm{~b}_{1}, \mathrm{a}_{2}, \mathrm{~b}_{2}$ with a condition of their bracing by the clamp $\Delta$.

2. Then, strain of an external ellipse by force $P$ is defined as double strain $\delta_{y 1}$ [delta] semiellipse with semiaxis and $\mathrm{a}_{2}, \mathrm{~b}_{2}$, with rigidly restricted ends with an assumption that an inner ellipse is absolutely rigid $\mathrm{J}_{1}=\infty$.

By a disclosure of static indeterminateness an expression of a lateral force $(\mathrm{X})$ is obtained, which is equal to a reaction in a support in a horizontal direction.

3. Then, considering an influence of an internal ellipse. Force $\mathrm{X}$ action leads to a joint deformation of both ellipses along $\mathrm{x}$ axis with following value

$$
\delta_{X}=\frac{2 X}{C_{1 X}+C_{2 X}},
$$

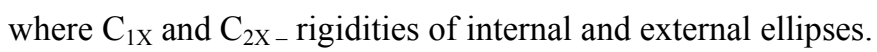

4. Knowing the value of a horizontal strain $\delta_{\mathrm{X}}$ [delta] and using relationships which were obtained for a single ellipse, determining force $X^{\prime}$, which might deform an external ellipse on a value of $\delta_{\mathrm{X}}$ [delta] with the assumption that there is no inner ellipse. Then, determining strain of an external ellipse in a vertical direction $\delta_{\mathrm{yII}}$ [delta].

5. The final equation for a determination of total strain of the system due to force $\mathrm{P}$ is as follows:

$$
\delta_{y \Sigma}=2 \cdot \delta_{y I}+\delta_{y I I} .
$$

For practical purposes, two cases of two ellipse system's strain are of interest, considering that ellipses, braced by a rigid clamp, are deformed jointly in a horizontal direction.

I. If $\Delta<\Delta_{0}$ [delta] an inner ellipse is deformed along semiaxis $\mathrm{a}_{1}$, and an external is deformed along semiaxis $\mathrm{b}_{2}$. Strain of both ellipses occurs in a direction of force $\mathrm{X}$, determining their rigidities:

$$
C_{1 X}=\frac{E J_{1}}{a_{1} b_{1} K_{11}} ; C_{2 X}=\frac{E J_{2}}{a_{2}^{3} K_{32}}
$$

II. If $\Delta>\Delta_{0}$, an inner ellipse is deformed along semiaxis $\mathrm{b}_{1}$, and an external is deformed along semiaxis $\mathrm{a}_{2}$. Strain of both ellipses occurs in a direction of force $\mathrm{X}$, determining their rigidities:

$$
C_{1 X}=\frac{E J_{1}}{a_{1}^{3} K_{31}}, C_{2 X}=\frac{E J_{2}}{a_{2} b_{2} K_{12}} .
$$

If $\Delta<\Delta_{0}$, [delta] the expression for load characteristics of two ellipse system is as follows: 


$$
P=\frac{\delta_{y \Sigma} \cdot E J_{2}}{a_{2} b_{2}^{2}\left(K_{5 a}+\frac{K_{6 a}}{\frac{a_{2}^{3} J_{1} K_{7 a}}{J_{2} a_{1}^{2} b_{1}}+1}\right)},
$$

where coefficients $\mathrm{K}$ are sets of parameters of ellipse's rings:

$$
\begin{gathered}
K_{5 a}=v_{52}-\frac{E\left(e_{2}\right) v_{32}^{2}+v_{22}^{2} v_{42}-2 v_{12} v_{22} v_{32}}{v_{42} E\left(e_{2}\right)-v_{12}^{2}} \\
K_{6 a}=\frac{\left(v_{12} v_{22}-E\left(e_{2}\right) v_{32}\right)\left(2 k_{b 2} v_{22}-v_{32}\right)}{v_{42} E\left(e_{2}\right)-v_{12}^{2}} \\
K_{7 a}=\frac{v_{42}-2 k_{b 2} v_{12}}{v_{51} \sqrt{1-e_{1}^{2}}-2 k_{a 1} v_{21}} .
\end{gathered}
$$

If $\Delta>\Delta_{0}$ [delta], then the expression for loading characteristics:

$$
P=\frac{\delta_{2 \Sigma}^{3} \cdot E J_{2}}{\left.K_{5 b}+\frac{K_{6 b}}{\frac{J_{1} a_{2}^{2} b_{2} K_{7 b}}{J_{2} a_{1}^{3}}+1}\right)} .
$$

where coefficients $\mathrm{K}$ are sets of parameters of ellipse's rings, which depends only on an external ellipse eccentricity and can be determined using the equation:

$$
\begin{gathered}
K_{5 b}=v_{42}-\frac{v_{12}^{2} v_{52}+E\left(e_{2}\right) v_{32}^{2}-2 v_{12} v_{22} v_{32}}{E\left(e_{2}\right) v_{52}-v_{22}^{2}} ; \\
K_{6 b}=\frac{\left(v_{12} v_{22}-E\left(e_{2}\right) v_{32}\right)\left(\frac{2 k_{a 2} v_{12}}{\sqrt{1-e_{2}^{2}}}-v_{32}\right)}{E\left(e_{2}\right) v_{52}-v_{22}^{2}} ; \\
K_{7 b}=\frac{v_{52} \sqrt{1-e_{2}^{2}}-2 k_{a 2} v_{22}}{v_{41}-2 k_{b 1} v_{11}} .
\end{gathered}
$$

Introducing, aside from aforementioned, two new criteria, which are convenient for a calculation of two ellipse system: dimensionless moment of inertia of a cross-section $\mu[\mathrm{mu}]$ and a ratio of big semiaxis of external and internal ellipses $\gamma$ [gamma]:

$$
\mu=\frac{J_{2}}{J_{1}}, \gamma=\frac{a_{2}}{a_{1}} .
$$

Expressions (24) and (28) are represented in a dimensionless form, using a set of criteria $(11,12,13)$ and (32), then, the expression for a determination of dimensionless force is obtained. For the case I, when $\Delta<\Delta_{0}$ [delta]

$$
\beta=\frac{8 \cdot E^{3}\left(e_{2}\right) \cdot \varsigma_{y \Sigma}}{\pi^{3}\left(1-e_{2}^{2}\right) \cdot\left(K_{5 a}+\frac{K_{6 a}}{\frac{\gamma^{3} K_{7 a}}{\mu \sqrt{1-e_{1}^{2}}}+1}\right)}
$$

For the case II, when $\Delta>\Delta_{0}[$ delta $]$ 


$$
\beta=\frac{8 \cdot E^{3}\left(e_{2}\right) \cdot \varsigma_{y \Sigma}}{\pi^{3} \cdot\left(K_{5 b}+\frac{K_{6 b}}{\frac{\gamma^{3} K_{7 b} \sqrt{1-e_{2}^{2}}}{\mu}+1}\right)}
$$

Initial distance between the rings:

$$
\Delta_{0}=R_{2}-R_{1}
$$

For an assembly clamps are used, in which rings will be installed at a distance $\Delta$ [delta] from each other. The rings will become deformed in accordance with their own nonlinear characteristics, until stresses in the clamp from both rings will become balanced. Introducing criteria of dimensionless length of bracing $\xi$ [xi], dimensionless radius $\lambda$ [lambda] and dimensionless moment of inertia of cross-section $\mu[\mathrm{mu}]$.

$$
\xi=\frac{\Delta-\Delta_{0}}{\Delta_{0}}, \lambda=\frac{R_{2}}{R_{1}}, \mu=\frac{J_{2}}{J_{1}} .
$$

Then, each ring's strain along a line of bracing can be found as follows. Presenting loading characteristics of both rings on the same graph (Figure 5). However, in a case of a dimensionless bracing length $\xi<0$ [xi], the graph for the first rings will be in a normal form, because it is stretched, and for the second ring the graph is in an upturned form, because it is compressed (see Figure 5). When dimensionless length of bracing $\xi>0$ [xi], the graph for the second ring is in a normal form and for the first one it is in an inverted from.

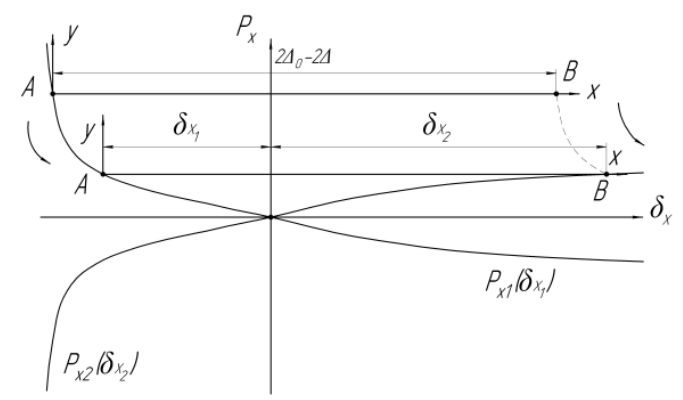

Figure 5. A determination of strain of rings in bracing

Introducing movable coordinate system xAy. Combining the origin of a coordinate system (point A) with the curve of loading characteristics for the first ring, as it is shown in figure 5. Designating in the selected coordinate system bracing length $\Delta$ in a form of a segment $\mathrm{AB}$, where point $\mathrm{B}$ has coordinates $\left(2 \Delta_{0}-2 \Delta ; 0\right)$ and then starting to move the coordinate system along the curve. As soon as point $B$ is engaging the curve of loading characteristics of the second ring, strains stresses of rings are becoming aligned and then will become equal to $\mathrm{P}_{0}$ and strains will distribute in a ratio $\delta_{1}: \delta_{2}$ [delta]. From mathematical perspective, this operation can be written in a form of a system of equations, which is correct for any length of bracing.

$$
\left\{\begin{array}{l}
P\left(\delta_{1}\right)=-P\left(\delta_{2}\right) \\
\delta_{2}-\delta_{1}=2 \Delta_{0}-2 \Delta
\end{array}\right.
$$

In the first approximation, replacing obtained elements of a complex shape with ellipses having semiaxes $a_{1}, b_{1}$ and $\mathrm{a}_{2}, \mathrm{~b}_{2}$, where

$$
\begin{cases}a_{1}=R_{1}-\frac{\delta_{1}}{2} ; b_{2}=R_{2}-\frac{\delta_{2}}{2}, \text { if } & \xi<0, \\ a_{2}=R_{2}+\frac{\delta_{1}}{2} ; b_{1}=R_{1}+\frac{\delta_{2}}{2}, \text { if } & \xi>0 .\end{cases}
$$

and, then, obtaining loading characteristics of assembled EDE, using FEM (Finite element method) (Figure 7).

Using mathematical software and graphs, obtained with FEM, it is easy to approximate functional expressions in a way that is desirable for a user and with a desired accuracy (Figure 6, 8).

where axis [beta] - Dimensionless force $\beta$; [zeta] - Dimensionless strain $\varsigma$; [gamma/mu] - Ratio of dimensionless 
axes of an ellipse to moment of inertia of cross-section $\gamma / \mu$

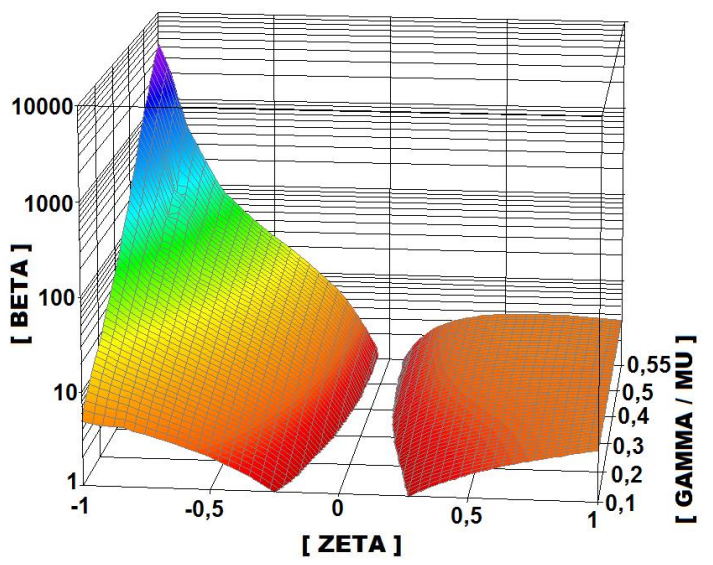

Figure 6. Graph of a relationship between dimensionless force $\beta$ [beta] and ratio of dimensionless axes of an ellipse to moment of inertia of cross-section $\gamma / \mu$ and dimensionless strain $\varsigma$ [zeta] for $\mathrm{P} \| \mathrm{b}$

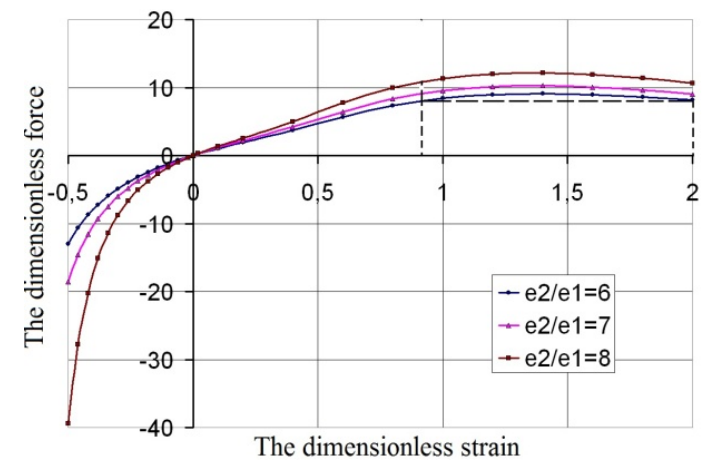

Figure 7. Graph of a relationship between $\beta=\mathrm{f}(\mathrm{e} 2 / \mathrm{e} 1, \varsigma y)$ with an area, where rigidity is close to quasi-zero

where axis [beta] - Dimensionless force $\beta$; [zeta] - Dimensionless strain $\varsigma$; [xi] - Dimensionless length of bracing $\xi$

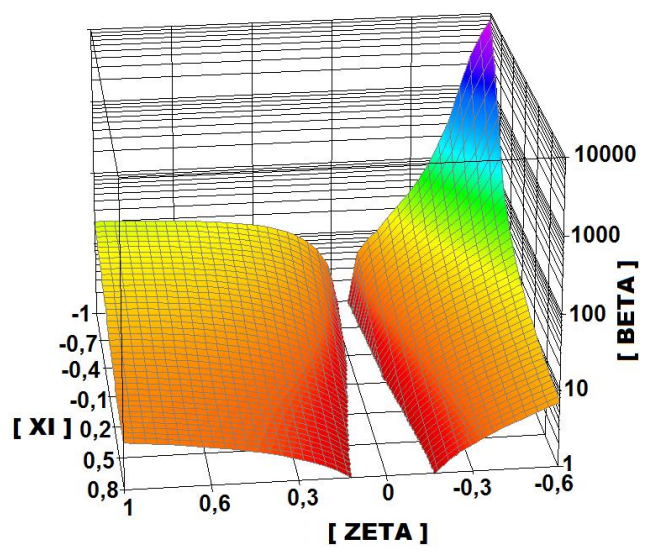

Figure 8. Graph of a relationship between dimensionless force $\beta$ [beta] and dimensionless strain $\varsigma$ [zeta] and dimensionless length of bracing $\xi[x i]$ for $\mu=8$

In conclusion, the graph of a relationship between dimensionless loading characteristics of the system and length bracing $\beta=f(\varsigma, \xi)$ is presented (see Figure 8). It is presumed the rings, which during their work belong to an ellipse type, in an initial moment belong to circular type. Considering the case when initial rings have equal rigidities $(\mu=8)[\mathrm{mu}]$.

\section{Results}

It is established that an implementation of two ring vibroinsulator with a variable degree of ellipticity of rings 
allows to obtain a significant difference of rigidity properties in one structure, which can be up to two orders. At the same time, a change of geometry of ellipses has much greater influence, than a change in an elastic element's cross-section moment of inertia.

It is established that use of bracing lengths $\Delta$ [delta] as a control parameter allows to change geometry of system and, as a consequence, intrinsic frequency of a system $\omega_{0}$ [omega] in 10 times, thus, ensuring effectiveness of vibroinsulation $E$ of an object, that is being protected against vibration, on a level of $99 \%$.

From the analysis of graphs, presented in Figure $6 \ldots 8$ it can be concluded that:

1. An increase of eccentricity is beginning to significantly influence rigidity, in a case $\mathrm{e}>0.8$, and in the same time, in a case of equally rigid, before clamp, rings, an external ellipse will have a greater influence.

2. An increase in a ratio of semiaxes $\gamma$ [gamma] increases rigidity of a vibroinsulator, but decreases working range of displacements, but in the same time an increase of dimensionless moment of inertia of cross-section $\mu$ $[\mathrm{mu}]$ leads to opposite results. The ratio $\gamma / \mu$ has a greater influence on rigidity characteristics of vibroinsulator in a case a force acts along small seimaxis of an ellipse $\left(\mathrm{P} \| \mathrm{b}_{2}\right)$, in a case a force acts along big semiaxis $\left(\mathrm{P} \| \mathrm{a}_{2}\right)$, eccentricity influence prevails. It is recommended to accept $\gamma>8$ [gamma] becasue of a small working range of displacements.

3. On the graphs, where a force acts along big semiaxis $\left(\mathrm{P} \| \mathrm{a}_{2}\right)$, in an area of compression, an area with rigidity, which is close to quasi-zero, is distinguishable (Figure 7). In a case, a force acts along small semiaxis of an ellipse $\left(\mathrm{P} \| \mathrm{b}_{2}\right)$, that area doesn't exist or has smaller size.

5. Two ring vibroinsulator has a great potential for a regulation. Thus, by changing only a parameter ellipticity of rings, a change of rigidity in almost 1000 times can be achieved, which is much greater, than in a case of a vibroinsulator, which consists of one ellipse ring; a change in the ratio $\gamma / \mu$ in a range from 0.15 to 0.55 allows to change rigidity in almost 300 times, and all of those without a significant change of a vibroinsulator's dimensions, which allows to achieve efficiency of vibroinsulation (E), that is close to $100 \%$.

\section{Discussion}

In the presented study following results were obtained. A change of bracing length, as it follows from the graph in Figure 8, can change rigidity of vibroinsulator in compression area in 5 times, in tension area in 370 times, that is about one-third from the theoretical capabilities of a vibroinsulator, which are discussed above, but, nonetheless, it is a good result (Ao et al. 2006, Belousov et al., 1985, Jiang et al., 2008, Mihir, 2011). The range of adjustment can be increased, by abandoning a circular shape of rings before bracing, i.e., making them initially in an ellipse shape, for example, using thermofixation (Ponomarev, 2003, Poppet al., 2003, Ulanov and Ponomarev, 2009).

Thus, a change of ellipse rings geometry through their bracing is an effective tool for management of dynamic properties mechanical system which is being protected from vibration.

That feature makes vibroinsulator a very interesting object, for a development on its basis vibroprotective manageable systems (Hakan et al., 2011, Jiang et al., 2005).

\section{Conclusions}

It is necessary to note, that the presented paper does not cover the entire list of issues which have to be considered in a case of a development of a methodology for a calculation of adjustable vibroprotective systems characteristics. In further studies, it is planned to investigate a problem of analytical determination of dampening characteristics of vibroinsulators. In addition, study of strain of multi-ring vibroinsulators, which is occurring with high speed, in order to use those principles in systems automated vibration damping is of interest.

\section{Acknowledgements}

This work was supported by the Ministry of education and science of the Russian Federation in the framework of the implementation of the Program of increasing the competitiveness of SSAU among the world's leading scientific and educational centers for 2013-2020 years.

\section{References}

Balyakin, V. B., Falaleev, S. V., \& Novikov, D. K. (2002). Air-tightness of secondary gas end seal assembly. Gazovaya Promyshlennost, 8, 56-58.

Barry, O., Zu, J. W., \& Oguamanam, D. C. (2014). Analytical and experimental investigation of overhead transmission line vibration. Journal of Vibration and Control. WOS: 1077546313517589. 
Belousov, A. I., \& Novikov, D. K. (1986). Selection of GTE rotor bearing hydrodynamic damper type. Soviet Aeronautics (English translation of Izvestiya VUZ, Aviatsionnaya Tekhnika), 29(3), 6-10.

Belousov, A. I., \& Falaleev, S. V. (1989). Gasostatic face seal with elastic working surface. Soviet Journal of Friction and Wear (English translation of Trenie i Iznos), 10(3), 34-38.

Belousov, A. I., Novikov, D. K., \& Eskin, I. D. (1981). Theory of hydrodynamic dampers with cylindrical and end slots. Soviet Aeronautics (English translation of Izvestiya VUZ, Aviatsionnaya Tekhnika), 24(3), 13-17.

Belousov, A. I., Balyakin, V. B., \& Novikov, D. K. (1985). Experimental study in pressure distribution in the oil film of short hydrodynamic damper. TRENIE \& IZNOS, 6(4), 648-652.

Belousov, A., Balyakin, V. B., \& Novikov, D. K. (1985). Experimental study of pressure distribution in lubricant layer of 'short' hydrodynamic dampers. Soviet Journal of Friction and Wear (English translation of Trenie $i$ Iznos), 6(4), 56-59.

Belousov, A. I., Ponomarev, Y. K., Pronichev, Y. N., \& Krypaev, D. G. (2009). Theory of an annular corrugated damper in the vibrator precession motion. Russian Aeronautics, 52(2). Date Views 17.02.2014 http://dx.doi.org/10.3103/S1068799809020111

Chegodaev, D. E., \& Ponomarev, Y. K. (1993). Multilayer shock absorbers with controllable elastic hysteresis characteristics. Izvestiya Vysshikh Uchebnykh Zavedenij. Aviatsionnaya Tekhnika, 2, 63-67.

Hakan, Y., Selçuk, M., \& Sadettin, K. (2010). Hybrid input shaping to suppress residual vibration of flexible systems. Journal of Vibration and Control, 18, 132. http://dx.doi.org/10.1177/1077546311403179

Hanche, O. H. (2004). Buckingham's pi-theorem. NTNU. Retrieved April 9, 2007. Date Views 01.09.2014.

Hongrui, A., Jiang, H., \& Ulanov, A. M. (2006). Estimation of the fatigue lifetime of metal rubber isolator with dry friction damping. Experimental Mechanics in Nano and Biotechnology, Parts 1 and 2, Vol. 326-328: 949-952. WOS: 000243448201010.

Hongrui, A., Jiang, H., Wei, W., \& Ulanov, A. M. (2006). Study on the damping characteristics of MR damper in flexible supporting of turbo-pump rotor for engine. ISSCAA 2006: 1st International Symposium on Systems and Control in Aerospace and Astronautics, 1-2, 618-622. WOS: 000237415000129.

Jiang, H. Y., Zhang, R. H., Zhao, K. D., \& Novikov, D. K. (2005). Analysis of damping characteristics of squeeze film damper with metal rubber. Tuijin Jishu/Journal of Propulsion Technology, 26(2), 174-177.

Jiang, H. Y., Hao, D. G., Xia, Y. H., Ulanov, A. M., \& Ponomarev, Y. K. (2008). Damping characteristics calculation method of metal dry friction isolators. Journal of Beijing Institute of Technology (English Edition), 17(2), 173-177.

Liu, T. Y., Chiang, W. L., Chen, C. W., Hsu, W. K., Lu, L. C., \& Chu, T. J. (2010). Identification and monitoring of bridge health from ambient vibration data. Journal of Vibration and Control, 17, 589. http://dx.doi.org/10.1177/1077546309360049

Marinin, A. V., Fedotov, V. M., Ostapenko, V. I., Serbin, V. A., Kuchkin, V. I., \& Ponomarev, Y. K. (1978). Producing steel St3sp for plates. Metallurgist, 22(2), 114-115. http://dx.doi.org/10.1007/BF01087856

Mihir, C. M. (2011). Free vibration of tapered isotropic rectangular plates. Journal of Vibration and Control, 18 , 76. http://dx.doi.org/10.1177/1077546310396800

Nurkan, Y., \& Sakman, L. E. (2006). Vibrations of a Rectangular Bridge as an Isotropic Plate under a Traveling Full Vehicle Model. Journal of Vibration and Control, 12, 83. http://dx.doi.org/10.1177/1077546306061411

Ponomarev, Y. K., Ermakov, A. I., Simakov, O. B., \& Mikhalkin, I. K. (2013). Metallic counterpart of rubber: A material for vibration and shock protection. Metal Science and Heat Treatment, 55(1-2). Date Views 17.04.2014. http://dx.doi.org/10.1007/s11041-013-9570-3

Ponomarev, Y. K., \& Kalakutsky, V. I. (2003). The multilayer all-metal vibration filters with elastic elements of a regular structure [Mnogosloinie celnometallicheskie vibroizoliatori s uprugimi elementami reguliarnoi strukturi]. Samara State Aerospace University, Samara, pp. 198.

Popov, E. P. (1986). The theory and calculation of the flexible elastic rods [Teoria i raschet gibkih stergnei]. Nauka, Moscow, pp. 296.

Popp, K., Lars, P., \& Walter, S. (2003). Vibration Damping by Friction Forces: Theory and Applications. Journal of Vibration and Control, 9, 419-448. 
Ulanov, A. M., \& Ponomarev, Y. K. (2009). Finite element analysis of elastic-hysteretic systems with regard to damping. Russian Aeronautics, 52(3), 264-270. http://dx.doi.org/10.3103/S1068799809030027.

Yurddas, A., Ozkaya, E., \& Boyac, H. (2012). Nonlinear vibrations and stability analysis of axially moving strings having nonideal mid-support conditions. Journal of Vibration and Control, 20, 518-534.

Zhdanov, I., Staudacher, S., \& Falaleev, S. (2013). An advanced usage of meanline loss systems for axial turbine design optimization. Proceedings of the ASME Turbo Expo 6 A. http://dx.doi.org/10.1115/GT2013-94323

\section{Copyrights}

Copyright for this article is retained by the author(s), with first publication rights granted to the journal.

This is an open-access article distributed under the terms and conditions of the Creative Commons Attribution license (http://creativecommons.org/licenses/by/3.0/). 